\title{
Assessment of RAPD Markers to Analyse the Genetic Diversity among Sunflower (Helianthus annuus L.) Genotypes
}

\author{
Ali Raza ${ }^{1 *}$, Haseeb Shaukat ${ }^{1}$, Qasim Ali², Madiha Habib ${ }^{1}$ \\ ${ }^{I}$ Centre of Agricultural Biochemistry and Biotechnology (CABB), University of Agriculture, Faisalabad, Pakistan. \\ ${ }^{2}$ Centre of Excellence in Molecular Biology (CEMB), University of Punjab, Lahore, Pakistan.
}

\section{A R T ICLE INFO}

\section{Research Article}

Received 23 November 2017

Accepted 13 January 2018

Keywords:

Sunflower

Diversity

PIC

RAPD

PCR

\begin{tabular}{l}
${ }^{*}$ Corresponding Author: \\
\hline E-mail: alirazamughal143@gmail.com
\end{tabular}

\begin{abstract}
A B S T R A C T
Genetic diversity estimation among different species is an important tool for genetic improvement to maximize the yield, desirable quality, wider adaptation, pest and insect resistance that ultimately boosting traditional plant breeding methods. The most efficient way of diversity estimation is application of molecular markers. In this study, twenty random amplified polymorphic DNA (RAPD) primers were utilized to estimate the genetic diversity between ten sunflower genotypes. Overall 227 bands were amplified by 20 primers with an average of 11.35 bands per primer. RAPD data showed $86.34 \%$ polymorophic bands and $13.65 \%$ of monomorophic bands. Genetic similarity was ranged from $50.22 \%$ to $87.22 \%$. The lowest similarity (50.22\%) was observed between FH-352 and FH-359 and the maximum similarity $87.22 \%$ was observed between A-23 and G-46. Polymorphic information content (PIC) values were varying from 0.05 to 0.12 with a mean of 0.09. Cluster analysis based on RAPD results displayed two major distinct groups 1 and 2. Group-2 contains FH-352 which was the most diverse genotype, while group-1 consists of few sub groups with all other genotypes. Ample diversity was found in all the genotypes. Present study reveals novel information about sunflower genome which can be used in future studies for sunflower improvement.
\end{abstract}

\section{Introduction}

Sunflower (Helianthus annuus L.) is the main cash crop and it belongs to the largest family of flowering plants, Asteraceae, a member of genus Helianthus. Spring and summer are most satisfactory seasons for the development of sunflower in Pakistan (Shah et al., 2013). Mainly this crop is grown for the yield of oil-seeds. This crop has scored $4^{\text {th }}$ position between oilseed crops followed by oil palm, brassica and soybean (FernándezMartínez et al., 2004). Seeds of this crop contain important fatty acids having $49 \%$ oil. Seed meals develop after oil isolation having protein, mineral, carbohydrate and mixed amino acids (Nisar et al., 2011). Advancement in (Helianthus annuus L.) genetics has seriously boosted the progress and approaches of new technologies for development of crops and its uses. Heterozygosity can be used greatly in oilseed crops for high production of oil. Hybrid cultivars are extra invariable, healthy, self-fertile and tolerance to leafage disease (Seiler et al., 2010).

In breeding programs, the genetic divergence study is important as it gives knowledge on genetic diversity quantum, which provides a platform for definite breeding purposes. Genetic diversity can be explained as grouping or classification of an individual or a population in contrast to other individuals or populations (AbdelMawgood, 2012). The information on genetic relatedness among parents increases the chance of heterosis in hybrids and decreases the possibility of reselection within related germplasm (Aremu, 2011). DNA markers are based on DNA sequence polymorphisms are most commonly known as molecular markers. These can be detected through different techniques such as PCR based technique, sequencing, Southern blotting and microarray. The diversity analysis of organisms can be determined by the variations in DNA sequence. Thus, the genetic diversity can be assessed directly by determining DNA polymorphisms (Hoshino et al., 2012).

Few molecular markers like simple sequence repeats (SSRs) (Iqbal et al., 2010; Garayalde et al., 2011), random amplified polymorphic DNA (RAPD) (Isaacs et al., 2003; Wangsomnuk et al., 2011a), target region amplification polymorphism (TRAP) (Yue et al., 2009; Yue et al., 2010), restriction fragment length polymorphism (RFLP) (Carrera et al., 2002), amplified fragment length polymorphism (AFLP) (Rachid et al., 2004; Dong et al., 2007; Vos et al., 1995) and inter simple sequence repeats (ISSRs) (Wangsomnuk et al., 2011b) have widely applied for marker-assisted selection (MAS), genomic evolution and used in some oilseed crops breeding research (SztubaSolińska, 2005). Mostly, genetic studies have separate principles and functions. Molecular process of heredity sources of crops and pets are performed with the help of 
PCR dependent study. RAPD markers are widely applied for genetic analysis due to their rapidity and accessibility (Carvalho et al., 2004). This marker is relative simple and quick technique that can be applied to estimate the heredity variations among plants with some essential properties (Lázaro and Aguinagalde, 1998). The objective of present research was to estimate the genetic diversity among sunflower genotypes using RAPD markers. That could be used for variety recognition and grouping.

\section{Materials and Methods}

\section{Plant Material}

Ten sunflower (Helianthus annuus L.) genotypes were selected to estimate the genetic diversity and polymorphism information (Table 1). Seeds of these genotypes were taken from Ayub Agricultural Research Institute (AARI), Faisalabad. All genotypes were grown in pots in the green house and young leaves of plants were collected and washed with double distilled water, immediately wrapped in aluminium foil and keep at $-20^{\circ} \mathrm{C}$ until DNA extraction.

\section{DNA Extraction from Leaf}

Total genomic DNA was extracted from each collected sample using standard $2 \mathrm{XCTAB}$ protocol with slight modification by adding two percent betamercaptoethanol into removal buffer reported by Li et al., (2007) To confirm the DNA extraction, samples were sprint on $1 \%$ agarose gel and DNA quantification was measured by using Nanodrop ND-1000 (Thermo Scientific). DNA dilutions $(25 \mathrm{ng} / \mu \mathrm{l})$ were prepared for $\mathrm{PCR}$ reaction.

\section{RAPD Analysis and Electrophoresis}

20 RAPD primers were optimized and used for DNA amplification of sunflower germplasm through (polymerase chain reaction) PCR. RAPDs were applied to determine the genetic diversity among sunflower cultivars. PCR reaction was consists of 3 steps as 1) denaturation temperature $95^{\circ} \mathrm{C}$ for one minute, 2) annealing temperature $36^{\circ} \mathrm{C}$ for 1 minute, 3) extension temperature $72^{\circ} \mathrm{C}$ for 2 minutes for 35 cycles. PCR was set to store the products at $4^{\circ} \mathrm{C}$. $6 \mu$ l loading dye $(0.50 \%$ bromophenole blue, $0.50 \%$ xylene cyanol) were added in products and mixed by microcentrifuge. PCR product was electrophoresed using $2 \%$ agarose gel at 100 voltage and amplified bands were seen on gel documentation system (Bio-Rad GDS).

\section{Statistical Data Analysis}

Bands scoring were done by using (1) for present and (0) for absent of bands in order to obtain the genetic similarity matrix. The genetic similarity was analysed through popgen32 software (version 1.44) (Yeh et al., 2002) to measure genetics distance among sunflower genotypes. Quantity of amplified fragments (QAFs), quantity of polymorphic fragments (QPFs), quantity of monomorphic fragments (QMFs) and percentage of polymorphic fragments (PPFs) was calculated by counting the reliable visible bands. Polymorphism information content (PIC) of every marker was measured according to Chesnokov et al., (2015) and Anderson et al., (1993). Dendrogram was created based on Unweighted
Pair Group Method with Arithmetic average (UPGMA) (Sneath and Sakol, 1973) by using popgen32 software (Version 1.44) for molecular relationship between ten genotypes (Yeh et al., 2002).

\section{Results}

\section{Level of Polymorphism}

A set of twenty RAPD primers were tested with ten individual DNA samples that amplified 227 loci. Out of 227 loci, 196 loci were polymorphic and 31 loci were monomorphic. Amplified fragments were ranged from eight (RAPD-L1) to twenty (RAPD-L20) with a mean of 11.35 bands per primer. Bands produced by RAPD primer L6 can be seen in (Figure 1).

\section{Effective Polymorphic Information}

For individual RAPD marker, quantity of amplified fragments (QAFs), quantity of polymorphic fragments (QPFs), quantity of monomorphic fragments (QMFs), percentage of polymorphic fragments (PPFs) and polymorphism information contents (PIC) was noticed. All 20 primers showed $86.34 \%$ polymorphic bands and 13.65\% monomorphic bands. Primer L3, L6, L8, L9 and L10 produced only polymorphic bands while others primers produced both monomorphic and polymorphic bands. Each primer template developed specific, effective and measurable band of changeable capacity. The level of polymorphism was different with different primers between ten genotypes. Distinction capacities for every single genotype were determined using PIC (Polymorphism Information Content) values. PIC values were varying from 0.05 to 0.12 with a mean of 0.09 (Table 2). Lower values of PIC with all primers indicated that primers were unequally distributed in population.

Genetic Similarity Matrix and Cluster Analysis

Dendrogram were created based on Unweighted Pair Group Method with Arithmetic average (UPGMA). A genetic similarity between ten genotypes was varying from $50.22 \%$ to $87.22 \%$. While, lowest similarity (50.22\%) was observed between FH-352 and FH-359 it means these two genotypes are relative dissimilar and the maximum similarity $87.22 \%$ was observed between A-23 and G-46 which indicates that these genotypes are closely related to each other (Table 3 ).

Dendrogram based on summarized data regarding differentiation among ten sunflower genotypes revealed that dendrogram is divided into two main groups 1 and 2 . Group-1 is further divided into two sub groups 3 and 4. Group-3 is also further divided into two sub groups 5 and 6 and group -5 consists of FH-106, while group- 6 further consists of FH-331 and A-49, which indicates these two genotypes have common origin. Group-4 is also further divided into two sub groups 7 and 8 . Group-7 is further subdivided into two sub groups 9 and 10, group-9 consists of FH-259 and A30 which indicating that genotypes have common origin, while group-10 consists of FH-385 and A-61. Group-8 consists of G-46 and A-23, both closely related genotypes. Group-2 consists of FH-352 and this genotype is not making cluster with any other genotype, which indicates that it is the most diverse genotype among all other genotypes (Figure 2). 
Table 1 List of sunflower genotypes used in this study for genetic analysis

\begin{tabular}{c|ccc}
\hline S. No. & Genotype code & S. No. & Genotype code \\
\hline 1 & FH-106 & 6 & G-46 \\
2 & FH-259 & 7 & A-23 \\
3 & FH-331 & 8 & A-30 \\
4 & FH-352 & 9 & A-49 \\
5 & FH-385 & 10 & A-61 \\
\hline
\end{tabular}

Table 2 Primer used in this study and information of generated fragments: Quantity of amplified fragments (QAFs), quantity of polymorphic fragments (QPFs), quantity of monomorphic fragments (QMFs), percentage of polymorphic fragments (PPFs) and polymorphism information contents (PIC)

\begin{tabular}{l|lccccc}
\hline \multicolumn{1}{c|}{ Primer } & Primer Sequence & QAFs & QPFs & QMFs & PPFs & PIC \\
\hline RAPD L1 & CGCAAGACCT & 8 & 7 & 1 & 87.50 & 0.12 \\
RAPD L2 & TCGGCGTCAA & 10 & 9 & 1 & 90.00 & 0.10 \\
RAPD L3 & CCAGCAGCTT & 8 & 8 & 0 & 100.00 & 0.10 \\
RAPD L4 & GACTGCACAC & 12 & 11 & 1 & 91.66 & 0.08 \\
RAPD L5 & ACGCAGGCAC & 10 & 8 & 2 & 80.00 & 0.11 \\
RAPD L6 & GAGGGAAGAG & 10 & 10 & 0 & 100.00 & 0.08 \\
RAPD L8 & AGCAGGTGCA & 14 & 14 & 0 & 100.00 & 0.06 \\
RAPD L9 & TGCGAGAGTC & 8 & 8 & 0 & 100.00 & 0.10 \\
RAPD L10 & TGGGAGATGG & 10 & 10 & 0 & 100.00 & 0.08 \\
RAPD L12 & GGGCGGTACT & 15 & 14 & 1 & 93.33 & 0.06 \\
RAPD L13 & ACCGCCTGCT & 9 & 8 & 1 & 88.88 & 0.11 \\
RAPD L14 & GTGACAGGCT & 10 & 7 & 3 & 70.00 & 0.12 \\
RAPD L15 & AAGACAGCGG & 8 & 8 & 0 & 100.00 & 0.10 \\
RAPD L16 & AGGTTGCAGG & 11 & 9 & 2 & 81.81 & 0.09 \\
RAPD L17 & AGCCTGAGCC & 17 & 11 & 6 & 64.70 & 0.08 \\
RAPD L18 & ACCACCCACC & 12 & 8 & 4 & 66.66 & 0.11 \\
RAPD L19 & GAGTGGTGAC & 10 & 9 & 1 & 90.00 & 0.09 \\
RAPD L20 & TGGTGGACCA & 20 & 16 & 4 & 80.00 & 0.05 \\
RAPD K11 & AATGCCCCAG & 14 & 11 & 3 & 78.57 & 0.08 \\
RAPD K12 & TGGCCCTCAC & 11 & 10 & 1 & 90.90 & 0.09 \\
Total & --- & 227 & 196 & 31 & --- & 1.81 \\
Percentage/Mean* & --- & $11.35 *$ & 86.34 & 13.65 & --- & $0.09 *$ \\
\hline
\end{tabular}

Table 3 Genetic similarity matrix (above diagonal) and genetic distance (below diagonal) for sunflower genotypes.

\begin{tabular}{l|cccccccccc}
\hline pop ID & FH-106 & FH-259 & FH-331 & FH-352 & FH-385 & G-46 & A-23 & A-30 & A-49 & A-61 \\
\hline FH-106 & $* * * *$ & 0.5815 & 0.6520 & 0.6035 & 0.6828 & 0.5991 & 0.6123 & 0.6211 & 0.6520 & 0.5859 \\
FH-259 & 0.5421 & $* * * *$ & 0.5771 & 0.5022 & 0.6344 & 0.5859 & 0.5903 & 0.7577 & 0.5330 & 0.6344 \\
FH-331 & 0.4277 & 0.5498 & $* * * *$ & 0.5639 & 0.6784 & 0.5859 & 0.6167 & 0.6167 & 0.7445 & 0.5903 \\
FH-352 & 0.5050 & 0.6888 & 0.5729 & $* * * *$ & 0.5683 & 0.5991 & 0.6123 & 0.6035 & 0.5727 & 0.5330 \\
FH-385 & 0.3815 & 0.4551 & 0.3880 & 0.5651 & $* * * *$ & 0.6256 & 0.6211 & 0.6564 & 0.6784 & 0.7445 \\
G-46 & 0.5123 & 0.5346 & 0.5346 & 0.5123 & 0.4691 & $* * * *$ & 0.8722 & 0.6344 & 0.6035 & 0.5991 \\
A-23 & 0.4905 & 0.5271 & 0.4833 & 0.4905 & 0.4762 & 0.1367 & $* * * *$ & 0.6388 & 0.6079 & 0.6211 \\
A-30 & 0.4762 & 0.2775 & 0.4833 & 0.5050 & 0.4210 & 0.4551 & 0.448 & $* * * *$ & 0.5991 & 0.6300 \\
A-49 & 0.4277 & 0.6292 & 0.2951 & 0.5574 & 0.3880 & 0.5050 & 0.4977 & 0.5123 & $* * * *$ & 0.5903 \\
A-61 & 0.5346 & 0.4551 & 0.5271 & 0.6292 & 0.2951 & 0.5123 & 0.4762 & 0.4621 & 0.5271 & $* * * *$ \\
\hline
\end{tabular}

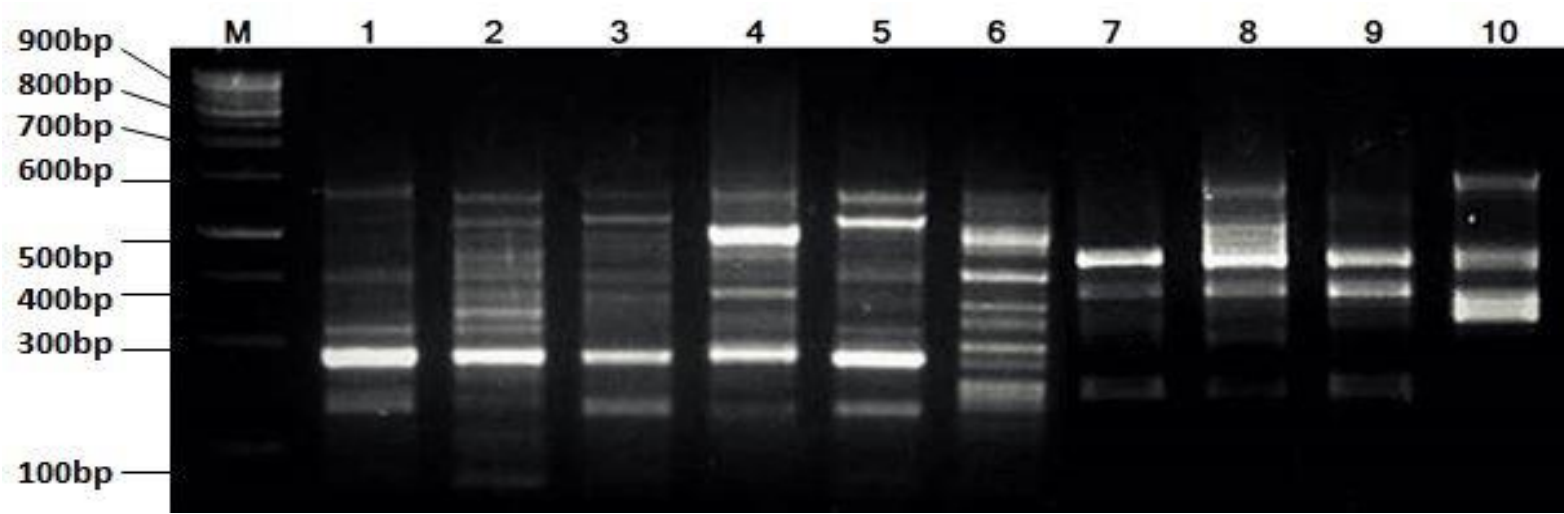

Figure 1 Agarose gel of amplified bands using Primer L6 on DNA of ten sunflower genotypes. Lane M: 1kb Ladder;

Lane 1: FH-106; Lane 2: FH-259; Lane 3: FH-331; Lane 4: FH-352; Lane 5: FH-385; Lane 6: G-46; Lane 7: A-23; Lane 8: A-30; Lane 9: A-49; Lane 10: A-61. 


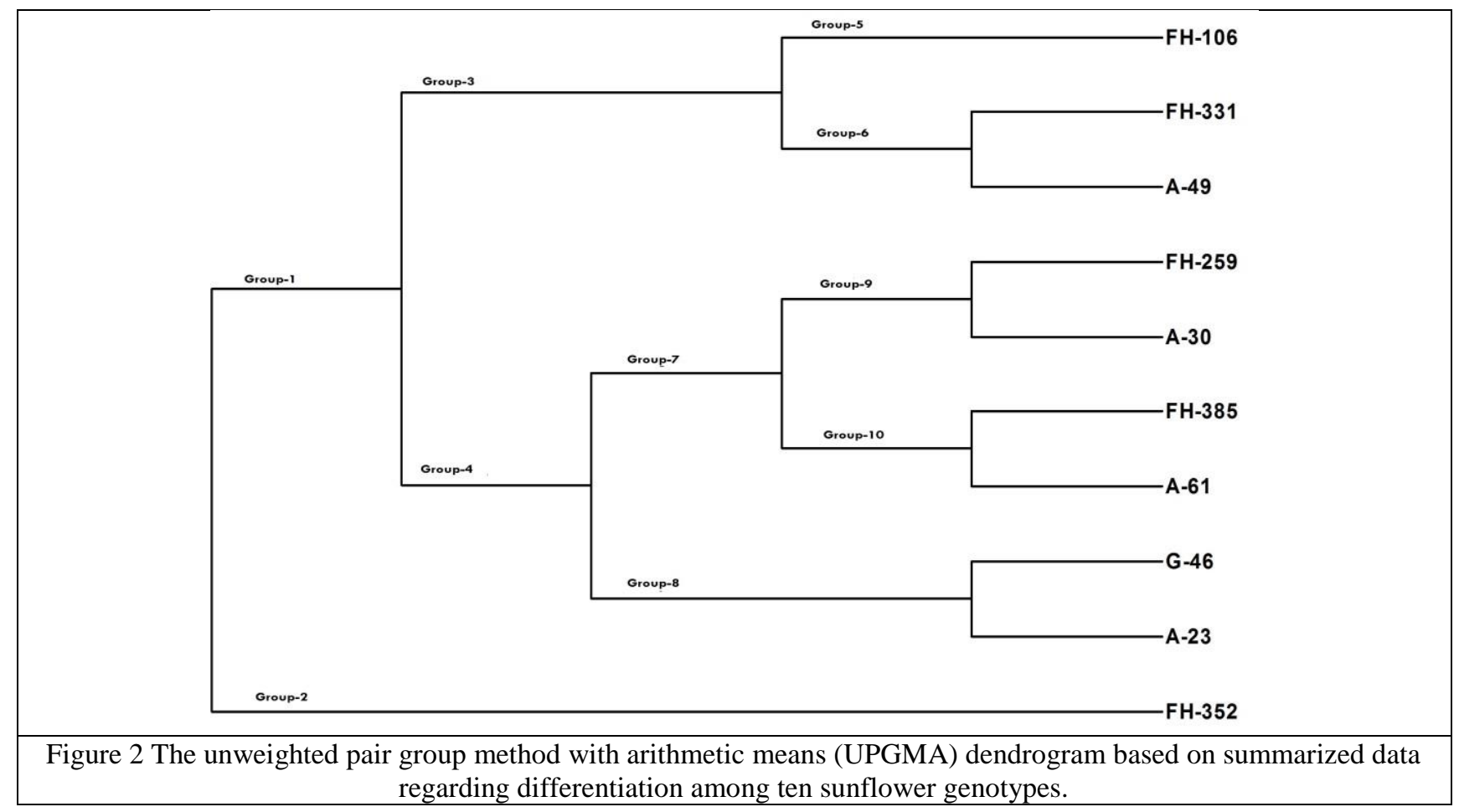

\section{Discussion}

Aim of present research were to estimate the genetic information using RAPD primers and data generated by these primers displays the effectiveness of primers and supports primer system for genetic analysis. Molecular markers are widely used to estimate the genetic variations, as molecular markers are self-determining for confounding results of environment factors. SSR and RAPD markers were used to observe the genetic distance between sunflower genotypes (Binsfeld et al., 2000; Popov et al., 2002) and identification of hybrids and getting information of variation for future breeding (Saftić-Panković, 2007).

Sunflower is very essential oil-seed crop after soybean and also major origin of edible oil around the globe. Molecular markers are used to estimate the genetic variations between genotypes and explore the clarity of seed, identification of cultivars and hybrids, markerassisted breeding (Barbara et al., 2007; Paniego et al., 1999; Baack et al., 2005). In present research, we assist RAPD primers to analyse the genetic diversity between local sunflower cultivars.

Kayis et al., (2010) compared the RAPD data with ISSR markers. In present study 20 RAPD primer were used that amplified 227 bands with a mean of 11.35 bands per marker. Low PIC in both RAPD and ISSR primers indicates the effectiveness of primer for genetic analysis, in this study the 0.09 average PIC value observed that varied from 0.05 to 0.12 ranges. Zhang et al., (2003) used SSR primers to analyse the genetic variation between one hundred and twenty four inbred cultivars of sunflower. Total 281 alleles were observed between 124 cultivars with an average of 3.5 alleles per primer. PIC values varying from 0.06 to 0.81 and these results are comparable to results of present study.
Mahmoud and Abdel-Fatah, (2012) used 3 different markers (RAPD, ISSR and SRAP) for genetic analysis between sunflower genotypes. Fifteen primers were used for genetic analysis and overall 183 bands were scored with a mean of 12.2 fragments per primer. Level of polymorphism was $46.45 \%$ display by 85 bands while other 98 bands (53.55\%) fragments was present in all genotypes and these results are closely related to present study.

Tang and Knapp, (2003) used 122 SSR markers to estimate the genetic variation between wild and cultivated genotypes and they observed 3.5 alleles per primer. Zhang et al., (2005) also use SSR markers to observe genetic diversity among sunflower genotypes and noticed amplified alleles ranged from 2 to 9 with a mean of 3.5 alleles per primer. Variation in results was based on many elements like difference in sample, sample expanse and procedure to estimate polymorphic level. In present study, we used leaves for DNA extraction and PIC was calculated to measure the polymorphism. Jannatdoust et al., (2016) evaluated molecular variation between fifty inter and intra genotypes of sunflower through SSR and retro-transposon primers. Amplified alleles were varying from 2-3 with a mean of 2.1 alleles per primer while retro-transposon primers display 7-15 alleles with a mean of 11.33 per allele.

In present study, we use twenty RAPD markers to estimate the genetic diversity among ten sunflower genotypes. RAPD data indicated $86.34 \%$ polymorphism and $13.65 \%$ monomorphism in all amplified bands. Genetic similarity was ranged from $50.22 \%$ to $87.22 \%$. Outcomes of this study committed that RAPD primers have the capacity to measure polymorphism, similarities and identification of genotypes using specific RAPD markers for sunflower genotypes. Finally, present 
research provides important knowledge for breeder to develop genotype resource.

\section{Acknowledgement}

Authors are grateful to Centre of Agricultural Biochemistry and Biotechnology (CABB), University of Agriculture, Faisalabad, Pakistan for providing necessary facilities during the research period.

\section{References}

Abdel-Mawgood AL. 2012. DNA based techniques for studying genetic diversity. In: Genetic diversity in microorganisms. Prof. Mahmut Caliskan ed.: In Tech.

Anderson JA, Churchill G, Autrique J, Tanksley S. and Sorrells M. 1993. Optimizing parental selection for genetic linkage maps. Genome., 36: 181-186.

Aremu C. 2011. Genetic diversity: a review for need and measurements for intraspecies crop improvement. J. Microbiol. Biotechnol. Res., 1: 80-85.

Baack EJ, Whitney KD, Rieseberg LH. 2005. Hybridization and genome size evolution: timing and magnitude of nuclear DNA content increases in Helianthus homoploid hybrid species. New Phytol., 167: 623-630.

Barbara T, Palma-Silva C, Paggi GM, Bered F, Fay MF, Lexer C. 2007. Cross-species transfer of nuclear microsatellite markers: potential and limitations. Mol. Ecol., 16: 3759-3767.

Binsfeld P, Wingender R and Schnabl H. 2000. Characterization and molecular analysis of transgenic plants obtained by microprotoplast fusion in sunflower. Theor. Appl. Genet., 101: 1250-1258.

Carrera AD, Pizarro G, Poverene M, Feingold S, León AJ. Berry S. 2002. Variability among inbred lines and RFLP mapping of sunflower isozymes. Genet. Mol. Biol., 25: 65-72.

Carvalho VP, Ruas CF, Ferreira JM, Moreira RM, Ruas PM. 2004 Genetic diversity among maize (Zea mays L.) landraces assessed by RAPD markers. Genet. Mol. Biol., 27: 228-236.

Chesnokov YV, Artemyeva A. 2015. Evaluation of the measure of polymorphism information of genetic diversity. Agri. Biol., 5: eng.

Dong G, Liu G, LI K. 2007. Studying genetic diversity in the core germplasm of confectionary sunflower (Helianthus annuus L.) in China based on AFLP and morphological analysis. Russ. J. Genet., 43: 627-635.

Fernández-Martínez J, Pérez-Vich B, Akhtouch, B, Velasco L, Muñoz-Ruz J, Melero-Vara J, Domínguez J. 2004. Registration of four sunflower germplasms resistant to race $\mathrm{F}$ of broomrape. Crop Sci., 44: 1033-1035.

Garayalde A, Poverene M, Cantamutto M, Carrera A. 2011. Wild sunflower diversity in Argentina revealed by ISSR and SSR markers: an approach for conservation and breeding programmes. Ann. Appl. Biol., 158: 305-317.

Hoshino AA, Bravo JP, Morelli KA, Nobile PM. 2012. Microsatellites as tools for genetic diversity analysis. In genetic diversity in microoganisms. InTech.

Iqbal A, Sadaqat H, Khan A, Amjad M. 2010. Identification of sunflower (Helianthus annuus, Asteraceae) hybrids using simple-sequence repeat markers. Genet. Mol. Res., 10: 102-106.

Isaacs SM, Manivannan N, Muralidharan V. 2003. Genetic diversity analysis using rapd marker in inbred lines of sunflower (Helianthus annuus L.). Helia., 26: 59-66.

Jannatdoust M, Darvishzadeh R, Ziaeifard R, Ebrahimi MA, Maleki HH, Gholinezhad E, Hatamnia AA. 2016. Analysis of genetic diversity and population structure of confectionery sunflower (Helianthus annuus L.) native to Iran. J. Crop Sci. Biotechnol., 19: $37-44$.

Kayis SA, Hakki EE, Pinarkara E. 2010. Comparison of effectiveness of ISSR and RAPD markers in genetic characterization of seized marijuana (Cannabis sativa L.) in Turkey. Afr. J. Agric. Res., 5: 2925-2933.
Lázaro A, Aguinagalde I. 1998. Genetic diversity in Brassica oleracea L.(Cruciferae) and wild relatives $(2 \mathrm{n}=18)$ using isozymes. Ann. Bot., 82: 821-828.

Li J, Yang J, Chen D, Zhang X, Tang Z. 2007. An optimized minipreparation method to obtain high-quality genomic DNA from mature leaves of sunflower. Genet. Mol. Res., 6: 1064-1071.

Mahmoud A, Abdel-Fatah B. 2012. Analysis of genetic diversity among sunflower genotypes using agro-morphological traits and molecular markers. Aust. J. Basic. Appl. Sci., 6: 419-432.

Nisar M, Hussain S, Nausheen Khan N, Siddiqui M. 2011. Chemical composition of open pollinated and hybrid population of sunflower (Helianthus annuus L.). Pak. J. Bot., 43(1): 157163.

Paniego N, Muñoz M, Echaide M, Fernandez L, Faccio P, Zandomeni R, Suarez E, Hopp E. 1999. Microsatellite development for sunflower. Plant and Animal Genome VII Conf. San Diego: Starford Univ. Press.

Popov V, Urbanovich OY, Kirichenko V. 2002. Studying genetic diversity in inbred sunflower lines by RAPD and isozyme analyses. Russ. J. Genet., 38: 785-790.

Rachid G, Gentzbittel L, Huang X, Sarrafi A. 2004. Genotypic variation and identification of QTLs for agronomic traits, using AFLP and SSR markers in RILs of sunflower (Helianthus annuus L.). Theor. Appl. Genet., 109: 1353-1360.

Saftić-Panković D. 2007. Application of molecular markers in sunflower breeding. Genetika., 39: 1-11.

Seiler G, Jan CC, Hu J. 2010. Basic information. Genetics, Genomics and Breeding of Sunflower. Clemson SC USA. 1-40.

Shah N, Aujla K, Ishaq M, Farooq A. 2013. Trends in sunflower production and its potential in increasing domestic edible oil production in Punjab, Pakistan. Sarhad J. Agric., 29: 7-13.

Sneath PH, Sokal RR. 1973. Numerical taxonomy. The principles and practice of numerical classification.

Sztuba-Solińska J. 2005. Molecular markers systems and their application in plant breeding. Kosmos., 54: 227-239.

Tang S, Knapp SJ. 2003. Microsatellites uncover extraordinary diversity in native American land races and wild populations of cultivated sunflower. Theor. Appl. Genet., 106: 990-1003.

Vos P, Hogers R, Bleeker M, Reijans M, Lee TVD, Hornes M, Friters A, Pot J, Paleman J, Kuiper M. 1995. AFLP: a new technique for DNA fingerprinting. Nucleic Acids Res., 23: 4407-4414.

Wangsomnuk P, Khampa S, Wangsomnuk P, Jogloy S, Mornkham T, Ruttawat B, Patanothai A, Fu YB. 2011a. Genetic diversity of worldwide Jerusalem artichoke (Helianthus tuberosus) germplasm as revealed by RAPD markers. Genet. Mol. Res., 10: 4012-4025.

Wangsomnuk PP, Khampa S, Jogloy S, Srivong T, Patanothai A, Fu YB. 2011b. Assessing genetic structure and relatedness of jerusalem artichoke (Helianthus tuberosus L.) germplasm with RAPD, ISSR and SRAP markers. Am. J. Plant Sci., 2: 753.

Yeh F, Yang R, Boyle T, Ye Zi Mao J. 2002. Popgen 32, microsoftware windows based freeware for population genetic analysis. Molecular Biology and Biotechnology Center, Edmonton.

Yue B, Cai X, Vick B, Hu J. 2009. Genetic characterization and molecular mapping of a chlorophyll deficiency gene in sunflower (Helianthus annuus). J. Plant Physiol., 166: 644-651.

Yue B, Vick B, Cai X, Hu J. 2010. Genetic mapping for the Rf1 (fertility restoration) gene in sunflower (Helianthus annuus L.) by SSR and TRAP markers. Plant Breeding., 129: 24-28.

Zhang L, Becquet V, Li S, Zhang D. 2003. Optimization of multiplex PCR and multiplex gel electrophoresis in sunflower SSR analysis using infrared fluorescence and tailed primers. Acta. Bot. Sin., 45: 1312-1318.

Zhang L, Clerc VL, Li S, Zhang D. 2005. Establishment of an effective set of simple sequence repeat markers for sunflower variety identification and diversity assessment. Can. J. Botany., 83: 66-72. 